\title{
Nicotine uptake by peppermint plants as a possible source of nicotine in plant-derived products
}

\author{
Dirk Selmar • Ulrich H. Engelhardt • Sophie Hänsel • \\ Claudia Thräne • Melanie Nowak • Maik Kleinwächter
}

Accepted: 26 February 2015 / Published online: 7 April 2015

(C) The Author(s) 2015. This article is published with open access at Springerlink.com

\begin{abstract}
Recently, nicotine has been detected in a large number of food crops and plant-derived products such as spices and herbal teas, but the origin of this nicotine is unknown. This study aimed to elucidate the putative sources of nicotine. We investigate the uptake of nicotine from nicotinecontaminated soils and tobacco smoke using peppermint plants, Mentha $\times$ piperita, as a model system in mulching and fumigation experiments. Results show that all the peppermint plants contain minor amounts of nicotine before treatment, but the experiments revealed that the plants also incorporate nicotine considerably from the soil as well as from tobacco smoke. These findings demonstrate for the first time that the reported occurrence of nicotine indeed may originate from tobacco. The incorporated nicotine was subsequently metabolised by the plants. Apart from the nutritional aspects, the results on nicotine uptake may also affect basic plant biology, because they demonstrate that alkaloids can be transferred from one plant, after its death, to another plant species.
\end{abstract}

Keywords Nicotine uptake $\cdot$ Alkaloids $\cdot$ Tobacco $\cdot$ Food safety $\cdot$ Mentha $\times$ piperita

\section{Introduction}

Until recently, nicotine was frequently used as an insecticide. However, due to toxicological concerns, the use of all

D. Selmar $(\triangle) \cdot S$. Hänsel $\cdot$ M. Nowak $\cdot$ M. Kleinwächter Institute for Plant Biology, TU Braunschweig, Mendelssohnstr. 4, 38106 Braunschweig, Germany

e-mail: d.selmar@tu-bs.de

U. H. Engelhardt $\cdot$ C. Thräne

Institute of Food Chemistry, TU Braunschweig, Schleinitzstr. 20, 38106 Braunschweig, Germany nicotine-containing pesticides has been banned in the EU since 2009 (Commission Decision 2009). No maximum residue level (MRL) was set, therefore the default MRL of $0.01 \mathrm{mg} \mathrm{kg}^{-1}$ d.w. $\left(=10 \mu \mathrm{g} \mathrm{kg}^{-1}\right.$ d.w. $)$ was applied. Surprisingly, a large number of plant-derived commodities had nicotine levels above the default MRL, e.g. peppermint, chamomile, oregano, etc. A compilation is provided by the European Food Safety Authority (EFSA 2011). The most striking examples of this report are summarised in Table 1. The first and most obvious assumption was that these nicotine levels were still due to nicotine-containing insecticides (Sheen 1988) illegally used after banning. However, this potential cause was disproved because nicotine was also found in many plant-derived commodities that had been produced under controlled and audited growth conditions. As relevant nicotine levels have also been reported in many different spice plants (EFSA 2011), the maximum residue level for nicotine in corresponding commodities was temporarily increased by the Commission to $0.05 \mathrm{mg} \mathrm{kg}^{-1}$ d.w. (Commission Regulation 2013). Unfortunately, there is no clear pattern that might point to either a regional distribution or to a systematic cause.

Apart from the illegal application of nicotine-containing insecticides, there are especially two other possibilities that may explain the occurrence of nicotine in food and spice plants. Either the plants incorporate the alkaloid from exogenous sources, or they are able to synthesise the alkaloid endogenously. In addition to nicotine-accumulating plants of the genus Nicotiana, the alkaloid has also been found in some other members of the Solanaceae family, such as potatoes, tomatoes and eggplants (Leete 1992). Although the corresponding nicotine concentrations in these vegetables (up to $0.24 \mathrm{mg} \mathrm{kg}^{-1}$ d.w.) $\left(0.24 \mu \mathrm{g} \mathrm{g}^{-1}\right.$ d.w.; Siegmund et al. 1999) are about 25 times higher than the official MRL, they are several magnitudes lower than those found 
Table 1 Occurrence and frequency of nicotine contaminations in plant-derived commodities. The data are extracted from the compilation published by the European Food Safety Authority (EFSA 2011)

\begin{tabular}{llll}
\hline Commodity & $\begin{array}{l}\text { Maximum value of } \\
\text { contamination }(\mu \mathrm{g} / \mathrm{g} \text { d.w. })\end{array}$ & $\begin{array}{l}\text { Samples containing } \\
\text { nicotine }\end{array}$ & $\begin{array}{l}\text { Number of analysed } \\
\text { samples }\end{array}$ \\
\hline Camomile flowers & 4.08 & $64 \%$ & 160 \\
Linden flowers & 1.08 & $98 \%$ & 43 \\
Rose hips & 0.88 & $81 \%$ & 81 \\
Black tea & 0.87 & $82 \%$ & 235 \\
Green tea & 0.44 & $84 \%$ & 93 \\
Sage leaves & 0.35 & $100 \%$ & 22 \\
Blackberry leaves & 0.28 & $9 \%$ & 45 \\
Mate leaves & 0.21 & $100 \%$ & 5 \\
Peppermint leaves & 0.11 & $58 \%$ & 118 \\
\hline
\end{tabular}

in tobacco (more than $10,000 \mu \mathrm{g} \mathrm{g}^{-1}$ d.w.; Saithoh et al. 1985). Yet, due to the occurrence of nicotine in so many different plant clades, it seems unlikely that the nicotine content is exclusively due to endogenous biosynthesis. Accordingly, we have to assume that the alkaloid may have come from exogenous sources, e.g., from cigarette smoke or from nicotine-contaminated soils. To date, there has been no evidence found to support this hypothesis. In this paper we used peppermint (Mentha $\times$ piperita) plants as a model system to investigate the possible uptake of nicotine from tobacco smoke or from nicotine-contaminated soils, e.g. as a result of discarded cigarette ends (Fig. 1).

\section{Materials and methods}

\subsection{Plant materials}

Peppermint plants (Mentha $\times$ piperita) were grown in greenhouses in pots $(\varnothing=15 \mathrm{~cm}$, containing about $1.5 \mathrm{~L}$ of a soilsand mixture, 2:1). Light intensity was about $300 \mu \mathrm{E} \mathrm{m}{ }^{-2} \mathrm{~s}^{-1}$ and followed a 16:8 long-day regime.

\subsection{Mulching with cigarette tobacco}

The commercial cigarette tobacco (American Spirit) was applied directly onto the soil by spreading the material evenly
Fig. 1 Experimental design of mulching experiments to study nicotine uptake from the soil. Commercial cigarette tobacco was applied directly onto the soil by spreading the material evenly across the surface $(\mathbf{a}, \mathbf{b})$, but avoiding any direct contact with the plants. The mulched soil was then covered with two layers of filter paper $(\mathbf{c}, \mathbf{d})$. The plants were watered every 2 days by pouring water through the filter paper
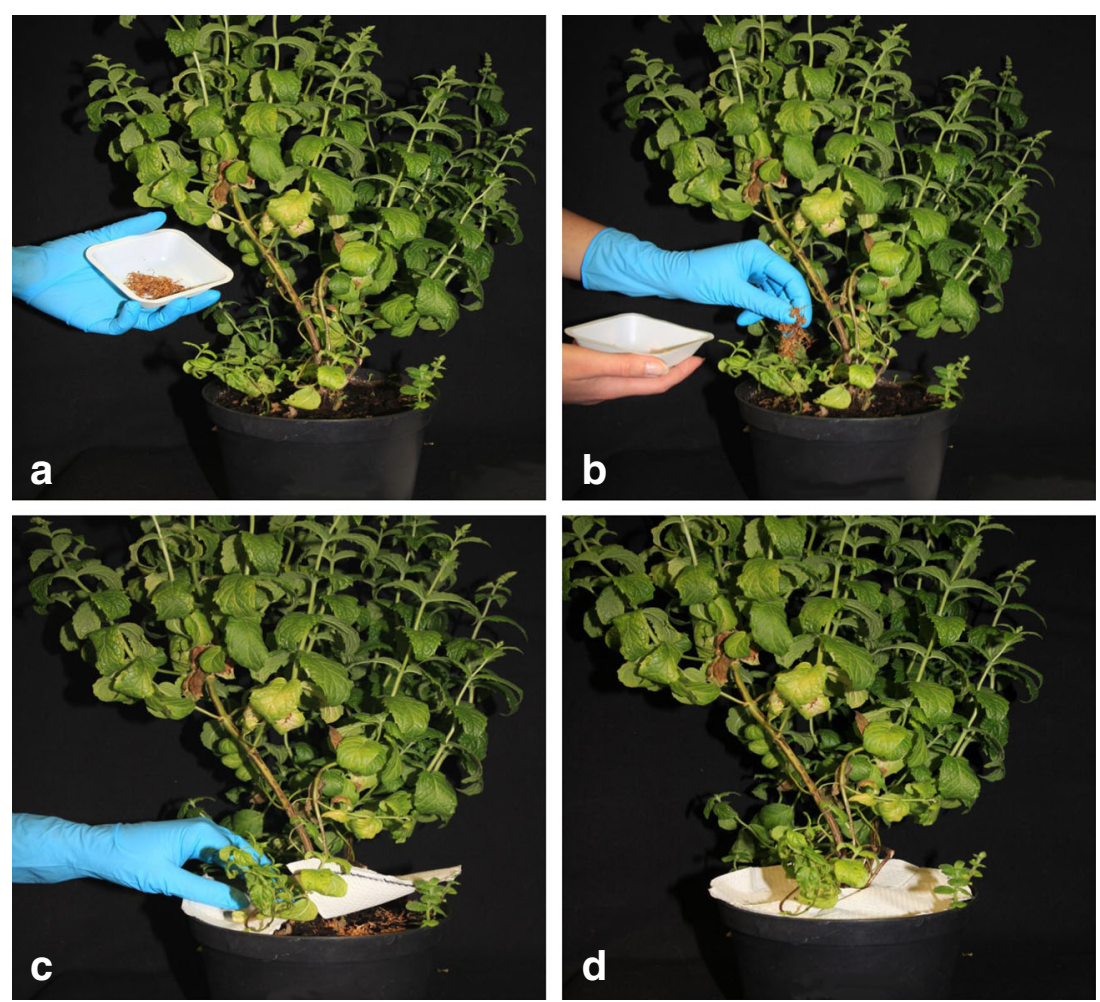
across the surface, but avoiding any direct contact with the plants. The mulched soil was then covered with two layers of filter paper (Fig. 1). The plants were watered every 2 days by pouring water through the filter paper. The plants were harvested 9, 16 and 25 days after mulching or prior to the mulching (0-sample). On each sample date, two samples, each consisting of the pooled leaves of three individual plants, were taken. Directly after harvest, the leaves were shock-frozen in liquid nitrogen and then ground using a mortar and pestle. All analyses were performed as independent double estimations. In addition, control plants were cultivated in a separate greenhouse without the mulching treatment (blank). The mean value of 0 -samples and blanks is denoted in the figures as "control" and represents the background level.

\subsection{Exposure to cigarette smoke}

Peppermint plants were cultivated in small greenhouses (floor size $15 \mathrm{~m}^{2}$, volume $22 \mathrm{~m}^{3}$ ). Eleven cigarettes were smoked in the greenhouse by probands within $2 \mathrm{~h}$. Samples were taken directly before ( 0 -sample) and at 1,2 and 8 days after fumigation. Two samples, each consisting of the pooled leaves of three individual plants, were taken at each sample date. Directly after harvest, the leaves were shock-frozen in liquid nitrogen and ground using a mortar and pestle. The control plants were cultivated in another greenhouse without exposure to cigarette smoke. The mean value of 0 -samples and blanks is denoted in the figure as "control" and represents the background level.

\subsection{Nicotine extraction}

The nicotine was extracted using a QuEChERS Kit (Quick, Easy, Cheap, Effective, Rugged and Safe-Agilent Technologies). Exactly $2.0 \mathrm{~g}$ of the ground plant material was extracted over $30 \mathrm{~min}$ in $9 \mathrm{~mL}$ water using a vortex mixer. After the addition of $100 \mu \mathrm{L}$ of internal standard $\left(\mathrm{d}_{4}\right.$-nicotine in acetonitrile), $400 \mu \mathrm{L}$ ammonia (5\%) and $10 \mathrm{~mL}$ acetonitrile, the mixture was shaken thoroughly (15 min) and ultrasonified (15 $\mathrm{min})$. To remove the water, the mixture was salted out by adding $4 \mathrm{~g}$ of $\mathrm{MgSO}_{4}$ (anhydrous) and $1 \mathrm{~g}$ of $\mathrm{NaCl}$. After vortexing ( $1 \mathrm{~min}$ ) and centrifugation $(5 \mathrm{~min}$ at $3500 \times \mathrm{g}$ ), $1 \mathrm{~mL}$ of the organic phase was transferred to a QuEChERS dSPE tube containing anhydrous $\mathrm{MgSO}_{4}$ and PSA (primary secondary amine). The sample was then vortexed (30 s) and centrifuged $(5 \mathrm{~min}$ at $3500 \times \mathrm{g}$ ). The supernatant was filtered $(0.2 \mu \mathrm{m}$, PTFE) before $50 \mu \mathrm{L}$ of formic acid were added. Then the sample was analysed by LC-MS.

\subsection{Nicotine quantification by LC-MS}

Liquid chromatography was conducted before mass spectrometric analyses using an Agilent HPLC System Series 1100
(Agilent Technologies, Waldbronn, Germany) connected to a HCT Ultra PTM Discovery System (Bruker Daltonics, Bremen, Germany) with electrospray ionisation (ESI) and ion trapping. A reversed phase phenyl-hexyl column (Luna ${ }^{\circledR}$ Phenyl-Hexyl, $3 \mu \mathrm{m}, 150 \times 2 \mathrm{~mm}$, Phenomenex, Aschaffenburg, Germany) with a gradient system consisting of $0.1 \%$ formic acid (A) and $0.1 \%$ formic acid in acetonitrile (B) was used to separate out the nicotine. The mobile phase conditions were the following: initial $10 \% \mathrm{~B}$ for $7 \mathrm{~min}$, linear increase from 10 to $100 \% \mathrm{~B}$ over $5 \mathrm{~min}$, hold for $6 \mathrm{~min}$ and reequilibration for $15 \mathrm{~min}$. The flow rate was $0.3 \mathrm{~mL} \mathrm{~min}^{-1}$ and $5 \mu \mathrm{L}$ of each sample was injected. For multiple reaction monitoring (MRM), the protonated form $[\mathrm{M}+\mathrm{H}]^{+}$of nicotine, $\mathrm{m} / z$ 163 , and nicotine- $\mathrm{d}_{4}, m / z 167$, were selected. The following ESI conditions, using the electrospray positive mode, were employed: capillary voltage $3.5 \mathrm{kV}$; dry gas flow $11 \mathrm{~L} \mathrm{~min}^{-1}$; dry gas temperature $350{ }^{\circ} \mathrm{C}$; nebulizer $60 \mathrm{psi}$; skimmer voltage $40 \mathrm{~V}$ and capillary exit $103.4 \mathrm{~V}$. The ultra scan data were processed using ESI Compass 1.3 software (DataAnalysis Version 4.0, QuantAnalysis Version 2.0).

\section{Results and Discussion}

\subsection{Nicotine uptake from the soil}

The mulching experiments were conducted to elucidate whether or not peppermint plants are able to take up nicotine from contaminated soils. Since a considerable number of peppermint samples contain significant amounts of nicotine (EFSA 2011; Table 1), reliable measurements of the background nicotine levels in the untreated controls were crucial. To estimate these background levels, a number of plants were harvested and analysed prior to the mulching experiments $(0-$ sample). Moreover, in parallel with the mulched plants, a further set of plants were cultivated without mulching (blank). In accordance with the EFSA study (2011), significant, but minor amounts of nicotine were present in all the samples before exposure and in the untreated plants ( 0 -samples, blanks and controls in Figs. 2, 3 and 4). This may be due to either endogenous biosynthesis or to contamination prior to the experiment. The average value of the 0 -samples and blanks, denoted as "control" in the figures, was about $0.03 \mu \mathrm{g} \mathrm{g}{ }^{-1} \mathrm{f} . \mathrm{w}$. (=30 $\mu \mathrm{g} \mathrm{kg}^{-1}$ f.w.), being within the concentration range found in tomatoes and peppers (Siegmund et al. 1999).

Analysis of the plants mulched with cigarette tobacco revealed that the alkaloid was significantly taken up by the plants (Fig. 2). After 9 days, the nicotine content of old leaves was more than $0.150 \mu \mathrm{g} \mathrm{g}^{-1}$ f.w. when $100 \mathrm{mg}$ of tobacco was applied to each pot (Fig. 2a) and nearly $1.500 \mu \mathrm{g} \mathrm{g}^{-1}$ f.w. when $1000 \mathrm{mg}$ of tobacco was added to the substrate (Fig. 2b). These alkaloid contents represent a tremendous increase in nicotine concentration compared to the background levels and show 
a

Nicotine uptake after application of $100 \mathrm{mg}$ tobacco nicotine ( $\mu \mathrm{g} / \mathrm{g}$ f.w.)
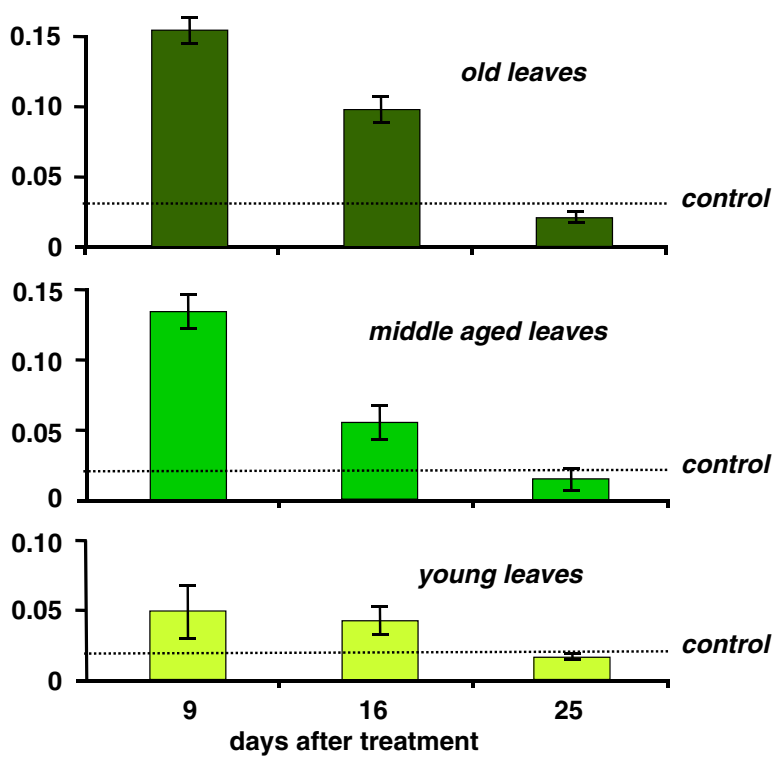

Fig. 2 Nicotine uptake from the soil. Peppermint plants were treated with different amounts of commercial cigarette tobacco (100 and $1000 \mathrm{mg}$ ). Each column represents the mean value of the leaves from six plants, analysed as two samples, each consisting of a mixture of three

that the peppermint plants had taken up massively nicotine from the soil and translocated it to the leaves. These results were confirmed by an independent experiment with a second set of 60 peppermint plants. The maximum nicotine concentration was again about $1.500 \mu \mathrm{g} \mathrm{g}{ }^{-1}$ f.w., which occurred when $1000 \mathrm{mg}$ of tobacco per pot was applied.

The translocation of the nicotine, taken up by the roots, into the leaves could either be performed by xylem or by phloem

\section{Dose-dependent uptake of nicotine}

nicotine ( $\mu \mathrm{g} / \mathrm{g}$ f.w.)

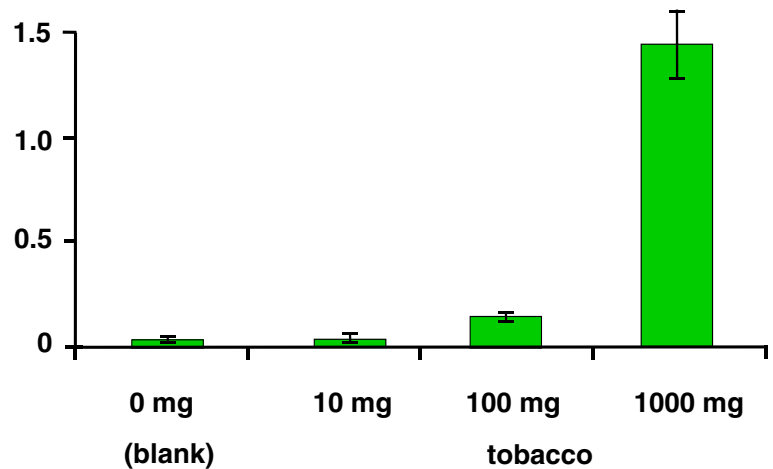

Fig. 3 Nicotine uptake is dose-dependent. Peppermint plants were mulched with different amounts of commercial cigarette tobacco $(0,10,100$ and $1000 \mathrm{mg}$, respectively). Analyses have been performed 9 days after mulching. Each column represents the mean value of six plant leaves, analysed as two samples, each consisting of a mixture of three individual plants. This very high reading was above the range where a linear relationship occurs (asterisk). Therefore, the correct values may be even higher b

Nicotine uptake after application of $1000 \mathrm{mg}$ tobacco nicotine ( $\mu \mathrm{g} / \mathrm{g}$ f.w.)
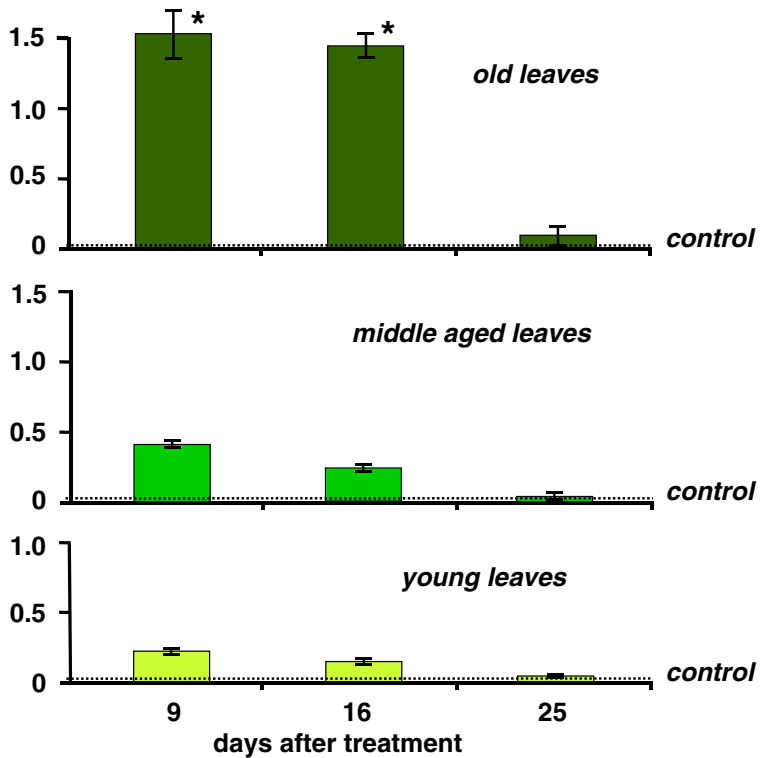

individual plants. Control corresponds to the background level, which was calculated as mean value of 0 -samples and blanks. These very high readings were above the range where a linear relationship occurs (asterisk). Therefore, the correct values may be even higher

transport. In the first case, nicotine would be passively transported by the transpiration flow, whereas in the second case, an active source-sink-translocation is required. A comparison between young, middle aged and older leaves clearly

\section{Nicotine uptake from cigarette smoke}

nicotine $(\mu \mathrm{g} / \mathrm{g}$ f.w.)

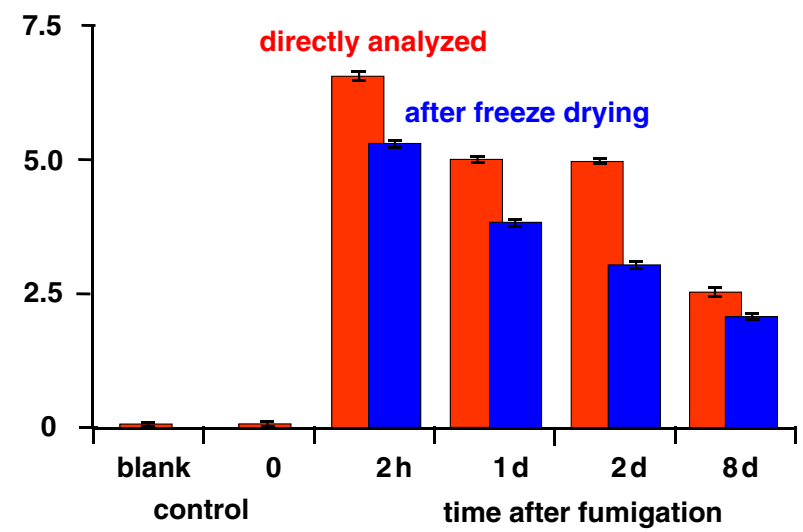

Fig. 4 Nicotine uptake from the gaseous phase. In a greenhouse, the peppermint plants were exposed to the smoke of 11 cigarettes within $2 \mathrm{~h}$ as outlined in section 2. Plants were harvested and analysed after 1, 2 and 8 days. Each column represents the mean value of six plant leaves. Control corresponds to the background level, which was calculated as mean value of 0 -samples and blanks. To distinguish between the nicotine which simply is absorbed on the surface and that which really is taken up by the cells, a lyophilisation step was included. Whereas the nicotine on the surface evaporates, the alkaloids taken up, remain - even under vacuum - in the plant material 
showed that the highest alkaloid concentrations were present in older leaves, i.e. the leaf tissues with the highest transpiration surface area. In contrast, the smaller, young leaves, which are physiological sinks, had far lower nicotine concentrations (Fig. 2a, b). From this, it can be concluded that the nicotine was translocated via the xylem into the leaves and that this process was driven by transpiration flow. The first analyses of guttation droplets, which demonstrated the occurrence of nicotine, confirmed this assumption. These findings are in accordance to Weidner and Teixeira da Silva (2006), who also found nicotine in the xylem sap, when nicotine was fed to a hydroponic system of Epipremnum.

A comparison of the nicotine content in peppermint plants mulched with different amounts of tobacco clearly revealed a dose-dependent response. The nicotine concentration in plants mulched with $10 \mathrm{mg}$ of tobacco was not significantly higher than the control, but the application of $100 \mathrm{mg}$ of tobacco resulted in a considerable increase (Fig. 3). Furthermore, the nicotine uptake increased tenfold when the amount of tobacco applied through mulching reached $1000 \mathrm{mg}$ of tobacco (Fig. 3).

Unexpectedly, the nicotine concentration decreased drastically as time progressed. To investigate whether or not the semi-volatile alkaloid simply evaporated, leaf samples were freeze-dried before analysis. The results showed that the amount of nicotine present in the freeze-dried leaf samples was nearly the same as in the leaf samples taken from nonlyophilised samples. Thus, nicotine evaporation could be ruled out. Therefore, it is most likely that the nicotine taken up by the roots and translocated into the leaves was metabolised by the peppermint plants. Indeed, catabolism of alkaloids is described to be a general feature of plants (e.g. Waller and Nowacki, 1978); however, such degradation solely was discussed to occur in plants that genuinely contain the corresponding alkaloids. Consequently, the metabolisation of "extrinsic alkaloids" is a novel idea, which actually is under study by applying ${ }^{14} \mathrm{C}$-nicotine to "non-nicotine plants".

In addition to their nutritional aspects, these results have also a great relevance for basic plant biology. They demonstrate that an alkaloid originally present in one plant, e.g. nicotine in tobacco, can be transferred from a dead plant into another plant species. Obviously, intact natural products released in the course of normal plant decay processes could be taken up by other, totally different plants. Previously, only the exchange of compounds between different living plants had been considered, which are involved in specific cause-action related interactions (Seigler 2006). These new insights should initiate a paradigm shift in our understanding of allelopathy. A passive, nondirected and functionally nonrelevant transfer of compounds, which are liberated during senescence and death of the donor plant and then taken up by an acceptor plant, has not been considered to date. Therefore, it is important to investigate whether horizontal transfers of natural products occur with other alkaloids and classes of natural products and to what extent. Further studies into other unknown plant-plant interactions may give insights into so far unexplained beneficial crop effects, e.g. those derived from the cocultivation of certain vegetables or from crop rotations. In this context, the impact of bio-fumigation should be re-evaluated.

\subsection{Nicotine uptake from cigarette smoke}

The fumigation experiments were conducted to elucidate whether or not plants are able to take up nicotine from the atmosphere. Peppermint plants were fumigated in a small greenhouse with the smoke from 11 cigarettes. Five plants were harvested prior to treatment and analysed ( 0 -sample). In parallel with the fumigated plants, control plants were also cultivated in a similar greenhouse, but without any fumigation (blank). The background nicotine level, denoted as control, was estimated as mean value of the 0-samples and blanks. Alike in the mulching experiments, minor amounts of nicotine were present in the control. The mean concentration of nicotine in the plants 1 day after fumigation was more than $6 \mu \mathrm{g} \mathrm{g}^{-1}$ f.w. ( $=6 \mathrm{mg} \mathrm{kg}^{-1}$ f.w.). If we assume that the average water content of the peppermint leaves was about $90 \%$, this concentration accounts for about $60 \mathrm{mg} \mathrm{kg}^{-1} \mathrm{~d} . \mathrm{w}$., which is a thousand times higher than the official MRL.

As found in the mulching experiments, the initial nicotine concentration in the fumigated peppermint plants decreased drastically as time progressed. One week after treatment, only one third of the initial nicotine content was left. This decrease in the fumigated plants corresponded to the decline of the nicotine levels in the mulched plants. Again, there are two possibilities: the nicotine remained on the surface of the leaves and simply evaporated over time, or the nicotine was taken up into the peppermint leaves and subsequently metabolised. Further freeze-drying experiments revealed that also after lyophilisation, nearly all nicotine remained in the material. This indicates a localisation of the alkaloid within the plant tissue. Therefore, the observed decline of the nicotine levels points to a metabolisation of nicotine, as it also was deduced for the mulched plants (see above). Yet, further experiments are necessary to verify this assumption.

\section{Conclusion}

For the first time, we have shown that peppermint plants take up nicotine from contaminated soils, and the resulting nicotine concentrations are several times higher than the maximum residue level set by the European authorities. Moreover, tremendously elevated nicotine levels were also detected after fumigation with cigarette smoke.

These results suggest that the widespread occurrence of nicotine in medicinal, spice and food plants may, at least in part, be due to exogenous nicotine sources. However, all the 
peppermint plants analysed in this study, including the untreated controls, contained minor amounts of the alkaloid, which suggested that peppermint plants may be able to synthesise nicotine endogenously. This assumption is supported by our finding that the Mentha plants are also able to metabolise the exogenous applied alkaloid, a process that is most likely based on a putative turnover of endogenously synthesised compounds.

In addition to the nutritional aspects, these results also demonstrate that a certain alkaloid could be translocated from one plant after its death to another plant species, even though it has no direct functional relevance. These coherences will affect the way we define allelopathy. Up to now, only the transfer of "functional substances" i.e. those, which have a certain impact on other plants, e.g. by inhibiting their growth or germination, had been considered and described by allelopathy (e.g. Seigler, 2006). In contrast, the transfer of all the substances, which naturally are leached out from plant litter into living plants never had been taken into account. Such horizontal transfers of natural products may give insights into hitherto unexplained processes, e.g. the beneficial effects of crop rotations or the cocultivation of certain vegetables.

Acknowledgments This research project was supported by the German Ministry of Economics and Technology (via AiF) and the FEI (Forschungskreis der Ernährungsindustrie e.V., Bonn, Germany). Project $\mathrm{AiF}-16720 \mathrm{~N} / 2$. We are grateful for the cooperation with and support by the German Tea Association (Hamburg) and the "Wirtschaftsvereinigung Kräuter-und Früchtetee e.V." (Hamburg). The technical support of Carina Wittke is greatly acknowledged.

Open Access This article is distributed under the terms of the Creative Commons Attribution License which permits any use, distribution, and reproduction in any medium, provided the original author(s) and the source are credited.

\section{References}

Commission Decision (2009) concerning the non-inclusion of nicotine in Annex I to Council Directive 91/414/EEC and the withdrawal of authorisations for plant protection products containing that substance. Official Journal of the European Union L 5/9 - 9.1.2009

Commission Regulation (2013) EU No 1004/2013 of 15 October 2013 amending Annexes II and III to Regulation (EC) No 396/2005 of the European Parliament and of the Council as regards maximum residue levels for 8-hydroxyquinoline, cyproconazole, cyprodinil, fluopyram, nicotine, pendimethalin, penthiopyrad and trifloxystrobin in or on certain products

European Food Safety Authority-EFSA (2011) (2011) Setting of temporary MRLs for nicotine in tea, herbal infusions, spices, rose hips and fresh herbs. EFSA J 9(3):2098

Leete E (1992) The biosynthesis of nicotine and related alkaloids in intact plants, isolated plant parts, tissue cultures and cell-free systems. Environ Sci Res 44:121-140. doi:10.1007/978-1-4615-3012-1_9

Saithoh F, Noma M, Kawashima M (1985) The alkaloid contents of sixty Nicotiana species. Phytochemistry 24:477-480. doi:10.1016/ S0031-9422(00)80751-7

Seigler DS (2006) Basic pathways for the origin of allelopathic compounds. In: Reigosa MJ, Pedrol N, González L (eds) Allelopathya physiological process with ecological implications. Springer, Heidelberg, pp 11-61. doi:10.1007/1-4020-4280-9 2

Sheen SJ (1988) Detection of nicotine in foods and plant materials. J Food Sci 53:1572-1573. doi:10.1111/j.1365-2621.1988.tb09328.x

Siegmund B, Leitner E, Pfannhauser W (1999) Determination of the nicotine content of various edible nightshades (Solanaceae) and their products and estimation of the associated dietary nicotine intake. $\mathrm{J}$ Agric Food Chem 47:3113-3120. doi:10.1021/jf990089w

Waller GR, Nowacki EK (1978) Metabolic (catabolic) modifications of Alkaloids by plants. In: Waller GR, Nowacki EK (eds) Alkaloid biology and metabolism in plants. Springer, Heidelberg, pp 183249. doi:10.1007/978-1-4684-0772-3_6

Weidner M, Teixeira da Silva JA (2006) Potential and limitations of ornamental plants for indoor-air purification. In: Teixeira da Silva JA (ed) Ornamental and Plant Biotechnology-Advances and Topical Issues, Volume IV. Global Science Books, Ikenobe, pp 54-63. 